International Journal of Applied Linguistics \& English Literature

ISSN 2200-3592 (Print), ISSN 2200-3452 (Online)

Vol. 1 No. 5; September 2012 [Special Issue on General Linguistics]

\title{
Book Review: Litosseliti, L. (2010). Research Methods In Linguistics. Continuum International Publishing Group Ltd. 228pp. ISBN 978-0-8264-8993-7 (paperback)
}

\author{
Mohammad Javad Riasati (Corresponding Author) \\ Department of Foreign Languages, Shiraz Branch, Islamic Azad University, Shiraz, Iran \\ E-mail: mjriasati2002@yahoo.com \\ Forough Rahimi \\ Department of Foreign Languages, Shiraz Branch, Islamic Azad University, Shiraz, Iran \\ E-mail: rahimi.forough@yahoo.com
}

Received: 20-06- 2012

Accepted: 03-07- 2012

Published: 03-09- 2012

doi:10.7575/ijalel.v.1n.5p.251

URL: http://dx.doi.org/10.7575/ijalel.v.1n.5p.251

\section{Introduction}

Research Methods in Linguistics presents the key concepts and principles of basic methods in linguistics research. It is an attempt to outline a comprehensive and organized resource for conducting research in linguistics. The issues covered in the book consist of a helpful collection of research methods in linguistics, which can benefit researchers and students in the field, and may appeal to both novice and experienced researchers.

\section{Book Overview}

The book is organized into three sections: Issues, Quantitative and Corpus Research Methods, and Qualitative Research Methods. The first section of the book covers two chapters examining some basic principles of research questions and tenets of quantitative and qualitative research methods. The following section contains three chapters which examine quantitative and corpus research methods in linguistics. They present a comprehensive overview of basic quantitative and corpus research designs, with the goal to introduce the practical stages required for researchers to comprehend and employ such designs. The last section has five chapters and discusses qualitative approaches in linguistics, with an emphasis on current major methods including discourse-analytic approaches, linguistic ethnography, interviews and focus groups, multimodal analysis, and narrative analysis.

\section{Chapters Overview}

Chapters 1-2

Chapter 1, written by Jane Sunderland, examines research questions, the rationale behind them, their origins, and their classification and implementation. A distinctive feature of the chapter is the wide range of examples of research questions in earlier sociolinguistic studies. The chapter also includes implications of different types of research questions for data collection and analysis.

Chapter 2, by Jo Angouri, is a meticulous investigation into how quantitative and qualitative methods can be integrated in linguistic research. The chapter is concerned with the use of triangulation and mixed methods, and discusses some of the benefits and hurdles in mixed-methods design. The chapter also discusses how mixed methodologies can contribute to richer findings and helps overcome some barriers involved in such type of research.

\section{Chapters 3-5}

Chapter 3, by Sebastian M. Rasinger, introduces the most common issues and conceptsof quantitative research. It starts with enumerating the major features of quantitative research with an emphasis on how it differs from qualitative type. Using examples from the field of linguistics, the chapter covers such issues as quantifiability: 
International Journal of Applied Linguistics \& English Literature

ISSN 2200-3592 (Print), ISSN 2200-3452 (Online)

Vol. 1 No. 5; September 2012 [Special Issue on General Linguistics]

the quality of being measurable. The chapter further discusses the issues of reliability, and validity of data and the most frequently used quantitative designs. It then focuses on the use of questionnaires in quantitative research, offering many practical ideas on how to design, phrase and code questionnaires.

Chapter 4, by ErezLevon, starts with a detailed discussion on how to formulate and test hypotheses in quantitative inquiries. The basic concepts needed to test hypotheses are also described. Another part of the chapter introduces two of the most frequently used statistical tests in quantitative studies: chi-square and t-tests. It also examines how they can be used and what they really indicate. The final section of this chapter is concerned with the interpretation of quantitative research results and how quantitative and qualitative methods can be triangulated in linguistic research.

Chapter 5, written by Paul Baker, starts with a discussion of theoretical principles underlying corpus linguistics techniques. Two approaches, corpus-based and corpus-driven, are introduced as important methodological approaches in corpus linguistics. Another part of the chapter examines different kinds of research questions corpus linguistics is concerned with. There are also some examples given on the use of corpora from past work in stylistics, discourse analysis, forensic linguistics, and language teaching. The final part of the chapter outlines some criticisms of corpus approaches. The chapter ends with a discussion of points that need to be taken into account while doing corpus analysis.

\section{Chapters 6-10}

In Chapter 6, Judith Baxter reviews four different approaches to discourse analysis in linguistics: Conversation Analysis (CA), Discourse Analysis (DA), Critical Discourse Analysis (CDA), and Feminist Post-structuralist Discourse Analysis (FPDA). The approaches are discussed in detail in terms of their background, underlying principles, major characteristics as well as their strengths and limitations. The chapter also discusses the relationship between the micro-analytical approaches investigating the details of linguistic interactions and macro-analytical approaches examining the broader social aspects of language.

Chapter 7, by Angela Creese, is concerned with linguistic ethnography and its contribution to the study of language. Two key issues in linguistic ethnography are discussed. The first issue deals with the interdisciplinary of linguistic ethnography; the second issue focuses on linguistic ethnography's social constructivist and post-modernist orientation. Another part of the chapter discuses methods of linguistic ethnography, including traditional ethnography and team ethnography. The final part of the chapter discusses the usefulness of integrating ethnography with other methods to arrive at richer data.

In Chapter 8, Nigel Edley and Lia Litosseliti provide a critical examination of the use of interviews and focus groups within social science and linguistics research. The authors first discuss the logic of using interviews, arguing that they are usually seen as a means of accessing phenomena that cannot be achieved through direct observation. Another part of the chapter deals with recent challenges against the use of interviews, specifically some problems inherent in the use of interview data. The authors then discuss several remarks in defense of interviews and focus groups and conclude that they can be seen as valuable research tools. The final part of the chapter discusses some of the pros and cons of both interviews and focus groups.

Chapter 9, by Jeff Bezemer and Carey Jewitt, discusses multimodal approaches to the study of linguistics and the centrality of multimodality in social linguistic traditions. The authors discuss social semiotic approaches to multimodality, which is the extension of social interpretation of language and its meanings to a range of modes of representation and communication employed in a culture. Another part of the chapter discusses steps involved in a social semiotic approach to multimodal research. This is illustrated using two examples to show how these steps are applied in research on classroom interaction and textbooks. The chapter ends with a discussion of the potentials and limitations of multimodal analysis.

Finally, in Chapter 10, Julio C. Gimenez introduces the key features of traditional and new emerging sociolinguistic approaches to the analysis of narratives, with an emphasis on narrative networks. The author starts with a review of the major definitions of narratives and then introduces two traditional analytical approaches: componential and functional analyses. The chapter then discusses the origins and theoretical principles of narrative networks, with a detailed description of how to design and analyze networks, and how they contribute to the critical analysis of narratives.

\section{Conclusion}

The organization of the chapters in the book makes each article useful for readers, since each chapter starts with a brief overview of the contents of the chapter before moving on to theoretical debates in the field. The papers 
International Journal of Applied Linguistics \& English Literature

ISSN 2200-3592 (Print), ISSN 2200-3452 (Online)

Vol. 1 No. 5; September 2012 [Special Issue on General Linguistics]

are well written and the topics chosen are interesting for those interested in the field. A salient feature of the book which makes it user-friendly is the large number of examples provided in detail to illustrate a certain point and make it more comprehensible. Furthermore, each chapter ends with a sources list entitled "Further Reading" that can be useful for those interested in the area. The book is a well-developed and highly informative one. Its overall structure is very comprehensible for the reader and can serve as a good resource to broaden the understanding of its users. Overall, the book can serve as a useful asset for many researchers, both novice and advanced. It can also be of great help to graduate and postgraduate students interested in learning and conducting research in linguistics, and can be of interest to scholars and practitioners working in the field of linguistics research.

\section{The Authors:}

Mohammad Javad Riasati is a PhD candidate in Applied Linguistics at UPM and a faculty member at Islamic Azad University, Shiraz Branch. He has published some books and articles and presented at some national and international conferences. His main areas of interest include second language acquisition and teacher education.

Forough Rahimi is a PhD candidate in Applied Linguistics at Islamic Azad University, Shiraz Branch, where she presently teaches. She is also a member of 'Young Researchers Club'. She has published some books and articles and presented at some national and international conferences. Her main areas of interest include critical applied linguistics, second language acquisition, teacher education, and specifically critical discourse analysis. 